\title{
Benchmarks
}

immunization strategy. Dev. Biol. (Basel) 104:171-179.

12.Staib, C., I. Drexler, M. OhImann, S. Wintersperger, V. Erfle, and G. Sutter. 2000.

Transient host range selection for genetic engineering of modified vaccinia virus Ankara. BioTechniques 6:1137-1148.

13.Tscharke, D.C. and G.L. Smith. 2002. Notes on transient host range selection for engeneering vaccinia virus strain MVA. BioTechniques 33:186-188.

14.Sutter, G., M. Ohlmann, and V. Erfle. 1995 Non-replicating vaccinia vector efficiently expresses bacteriophage T7 RNA polymerase. FEBS Lett. 371:9-12.

We thank Robert Baier for excellent technical help. This work was supported in part by grants from the Deutsche Forschungsgemeinschaft and the European Community (QLK2-CT-2002-01867). Address correspondence to Dr. Gerd Sutter, GSF - Institute for Molecular Virology Trogerstr. 4b, 81675 Munich, Germany. e-mail: sutter@gsf.de

Received 20 December 2002; accepted 22 January 2003.

Caroline Staib $^{1,2}$, Marianne Löwel $^{1}$, Volker Erfle ${ }^{1,2}$, and Gerd Sutter ${ }^{1,2}$

${ }^{1}$ GSF - National Research Center for Environment and Health

${ }^{2}$ Technical University Munich Munich, Germany

\section{Genomic DNA Labeling for Hybridization with DNA Arrays}

\section{BioTechniques 34:700-704 (April 2003)}

In an attempt to optimize parameters of genomic DNA (gDNA) hybridization to bacterial DNA arrays, we found that the method of gDNA labeling, especially gDNA denaturation, is the most crucial step for the quality of the process. The classical method for generating the random primer hybridization probe suggests one boils DNA in water or weakly buffered solution for 2-5 min (1). In addition, fragmentation of the gDNA, for example by sonication to an average length of $500-1500 \mathrm{bp}$, is also thought to be necessary for the method. Working with whole genome arrays of Bacillus subtilis, we found that boiling should be avoided. As an alternative, we suggest that an alkaline denaturation step before the random primer reaction is preferable and sufficient without recourse to sonication.

We illustrate these points by presenting the results of array hybridizations and by analyzing the labeled gDNA directly. Our B. subtilis arrays were prepared on nylon membranes similar to ones described previously $(2,3)$ and contained PCR fragments of 4100 ORFs from B. subtilis obtained from Eurogentec (Seraing, Belgium). gDNA was isolated from $1.5 \mathrm{~mL}$ of a logarithmic culture (4) using Genomictip 20 (Qiagen, Hilden, Germany), following the manufacturer's instructions, and recovered in TE buffer. After purification, DNA was either freshly used or stored for no longer than two days at $4^{\circ} \mathrm{C}$. All DNA samples obtained by this method typically had an $\mathrm{A}_{260} / \mathrm{A}_{280}$ ratio about 1.8. The purified DNA appears as a single band near the wells after $0.6 \%$ agarose gel electrophoresis, with an estimated size of approximately $50 \mathrm{~kb}$. All buffers were prepared with nanopure (divalent cation-free) nuclease-free water.

Purified gDNA was either directly labeled using the Prime-It ${ }^{\mathbb{R}}$ II kit (Stratagene, La Jolla, CA, USA) or denatured using the procedure described here. gDNA (200 ng) was incubated with 200 $\mathrm{mM} \mathrm{NaOH}$ in a total volume of $50 \mu \mathrm{L}$ for $20 \mathrm{~min}$ at room temperature or for $10 \mathrm{~min}$ at $70^{\circ} \mathrm{C}$. The mixture was then precipitated by adding $20 \mu \mathrm{L} 5 \mathrm{M}$ ammonium acetate $(\mathrm{pH} 7.5)$ and $175 \mu \mathrm{L}$ ethanol for $2 \mathrm{~h}$ at $-20^{\circ} \mathrm{C}$. After centrifugation at $13000 \times \mathrm{g}$ at $4^{\circ} \mathrm{C}$ for $20 \mathrm{~min}$ and washing with $70 \%$ ethanol, the pel-

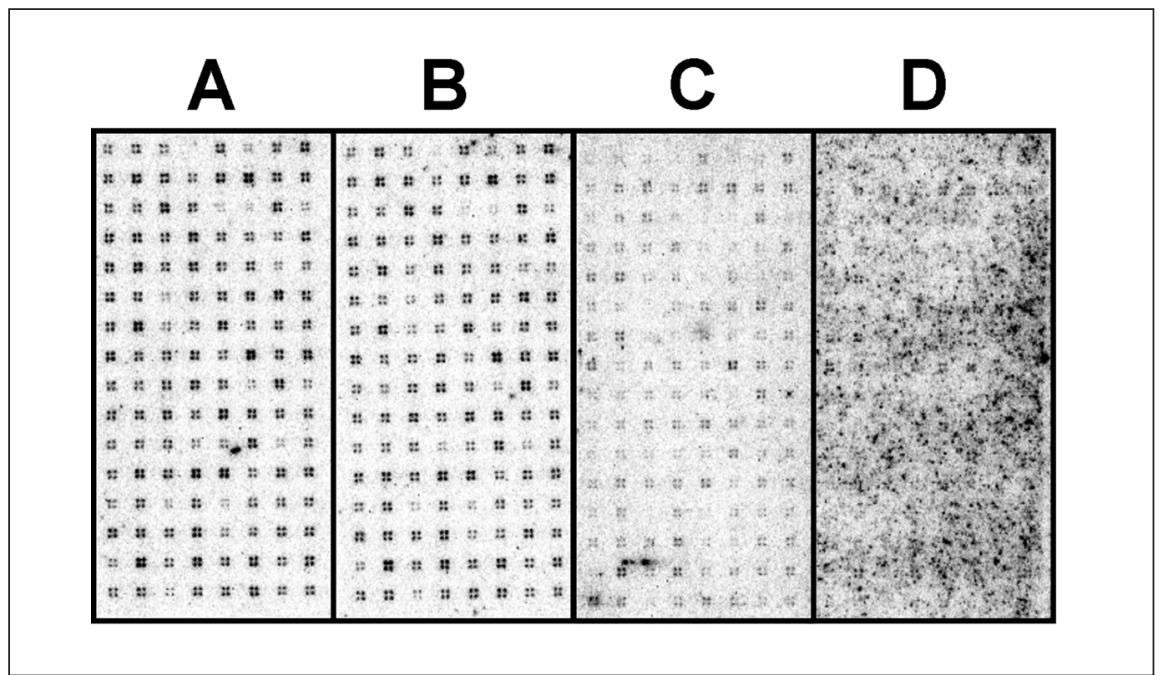

Figure 1. Hybridization of radioactive labeled gDNA to nylon DNA arrays. $B$. subtilis gDNA samples were differently denatured before random primed labeling. The same part of the arrays is shown. (A) $\mathrm{NaOH}$ treatment at room temperature for $20 \mathrm{~min}$ and (B) at $70^{\circ} \mathrm{C}$ for $10 \mathrm{~min}$ before labeling. We also used the protocol described by the manufacturer of Prime-It II (Stratagene) with slight modifications: denaturation of DNA was performed either by incubation for $5 \mathrm{~min}(\mathrm{C})$, as recommended, or (D) for $10 \mathrm{~min}$ in a boiling water bath. Labeling and hybridization of all samples were performed as described in the text. 


\section{Benchmarks}

let was resuspended in $60 \mu \mathrm{L} 10 \mathrm{mM}$ Tris- $\mathrm{HCl}, \mathrm{pH}$ 7.5. Labeling was carried out by mixing $10 \mu \mathrm{L}$ (or $25 \mathrm{ng}$ ) denatured gDNA with $10 \mu \mathrm{L} 5 \times$ random hexamer solution, $10 \mu \mathrm{L} 5 \times \mathrm{dCTP}$ buffer $(0.1 \mathrm{mM}$ dTTP, dATP, dGTP each), and $50 \mu \mathrm{Ci}\left[\alpha-{ }^{33} \mathrm{P}\right] \mathrm{dCTP}(3000$ $\mathrm{Ci} / \mathrm{mmol}$; Perkin Elmer Life Sciences, Boston, MA, USA) and $1 \mu \mathrm{L}$ Exo(-) Klenow DNA polymerase in a total volume of $50 \mu \mathrm{L}$ for labeling. After labeling, the reactions were stopped with 2 $\mu \mathrm{L}$ Stop Solution (Stratagene) and purified on G50 gel filtration spin columns (G50 Mini Quick Spin ${ }^{\mathrm{TM}}$ Columns; Roche Applied Science, Mannheim, Germany). Measurements of the incorporation rates by calculating radioactive material before and after G50 gel filtration purification were similar to the values obtained with 5\% TCA precipitation (5). Incorporation was in the range of $50 \%-60 \%$ independently from the methods of labeling. Hybridization was performed in $20 \mathrm{~mL}$ for $20 \mathrm{~h}$ at $50^{\circ} \mathrm{C}$ in a buffer containing $50 \%$ formamide $6 \times$ SSC, 7\% SDS, and $50 \mathrm{mM}$ sodium phosphate, $\mathrm{pH}$ 7.5. After hybridization, arrays were washed twice for $15 \mathrm{~min}$ in $2 \times$ SSC, $1 \%$ SDS, and then twice for 15 min in $0.1 \times \mathrm{SSC}, 0.5 \% \mathrm{SDS}$ at $65^{\circ} \mathrm{C}$. The dried arrays were then exposed to image screens, and the images were scanned by Bas5000 (Fuji Film, Raytest, Straubenhardt, Germany).

As shown in Figure 1C, the standard random primer labeling protocol provided sufficient results for hybridization of the whole gene array. However, our previous experience showed that some ORFs in the range of $1 \mathrm{~kb}$ could not be detected using this method, which could be explained by the low efficiency of the labeling reaction or incomplete denaturation of gDNA. Because the incorporation rate with a random primer reaction has already reached a plateau after $10 \mathrm{~min}$, we reasoned that denaturation of the gDNA may be crucial. We tried to improve denaturation by boiling the samples for a longer time. Surprisingly, after only $10 \mathrm{~min}$ of boiling, we observed strong nonspecific background signals (Figure 1: compare $\mathrm{C}$ and D) upon hybridization with the nylon membrane. Further increasing the boiling time had a similar effect (not shown). It is worth mentioning that this type of background was very reproducible with different $B$. subtilis gDNA isolates. In contrast, when using alkali denaturation of gDNA before labeling, we observed almost no nonspecific membrane binding (Figure 1A) and a higher signal-to-noise ratio. Subsequent heating to $70^{\circ} \mathrm{C}$ in alkali solution did not detract from or improve the quality of hybridization (Figure 1B).

We speculated that depurination and fragmentation might be responsible for the observed effect. It is known that water is a poor buffer and heating in water itself causes depurination of nucleic

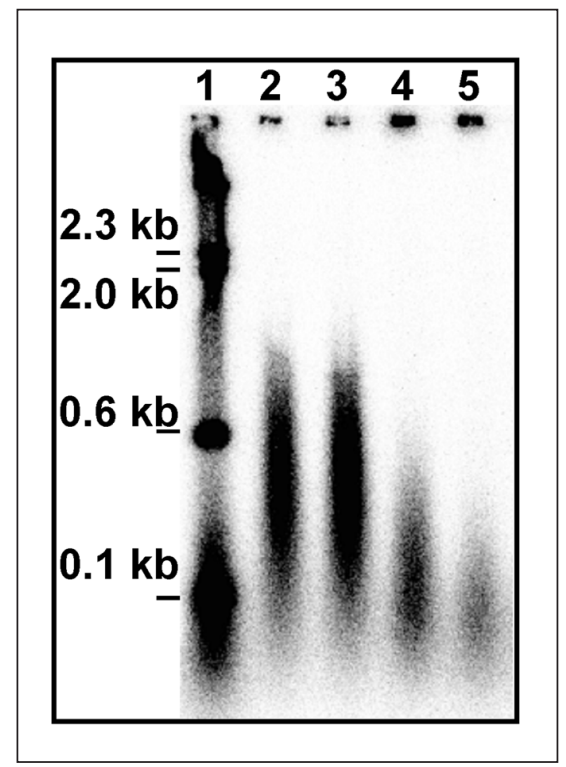

Figure 2. Fragment length depends on different treatments of gDNA before labeling. One microliter of labeled and G50 purified genomic DNA (see the text) was added to $10 \mu \mathrm{L} 50 \mathrm{mM} \mathrm{NaOH}$, $1 \mathrm{mM}$ EDTA, heated at $70^{\circ} \mathrm{C}$ for $5 \mathrm{~min}$, and then mixed with $2 \mu \mathrm{L}$ loading buffer ( $30 \%$ glycerol, $100 \mathrm{mM}$ EDTA, $0.125 \%$ bromophenol blue). Equal aliquots of $250000 \mathrm{cpm}$ were loaded on the gel. Electrophoresis was performed in $50 \mathrm{mM}$ $\mathrm{NaOH}, 1 \mathrm{mM}$ EDTA buffer at $1 \mathrm{~V} / \mathrm{cm}$ for $18 \mathrm{~h}$ at $4^{\circ} \mathrm{C}$. The radioactive labeled DNA was transferred in $20 \times \mathrm{SSC}$ to a nylon membrane (Hybond $\mathrm{N}+{ }^{\circledR}$; Amersham Biosciences, Freiburg, Germany) and detected by exposure to a phosphor image screen (Fuji, Raytest). Lane 1, lambda DNA digested with HindIII and end-labeled as described by Sambrook et al. (5) was used as a molecular weight marker. The other lanes correspond to the different gDNA treatments before labeling: lane 2 . treatment with $\mathrm{NaOH}$ at room temperature for 20 min; lane 3 , at $70^{\circ} \mathrm{C}$ for $10 \mathrm{~min}$ as described in the text; lane 4 , incubation in a boiling water bath for $5 \mathrm{~min}$; and lane 5, for $10 \mathrm{~min}$ following the PrimeIt II protocol described by Stratagene. The incorporation rates for all four labeling conditions were $51 \%, 57 \%, 54 \%$, and $55 \%$, respectively. 


\section{Benchmarks}

acids (6). Under the conditions usually used for classical random priming $\left(99^{\circ} \mathrm{C}\right.$ for $\left.5 \mathrm{~min}\right)$, it is very likely that DNA would be partially depurinated and also partially fragmented (7). Alkali denaturation of DNA is considered to be much milder, and no depurination is observed. Even heating at elevated temperatures in alkali solutions has little effect on the depurination rate (6).

Figure 2 supports this hypothesis. The fragments synthesized following alkali denaturation are generally longer, estimated as 200-1000 bp, in comparison to the 100-300 bp fragments obtained using the standard random primer protocol. However, it is not clear how and why short fragments should increase the nonspecific background on nylon membranes. One can also see that most of the DNA material remains in the wells, which may indicate, for example, the formation of a DNA network induced by boiling. It is tempting to speculate that the same effect that prevents DNA from entering the agarose gel is responsible for nonspecific bind- ing to the nylon membrane.

Surprisingly, the use of "cold" dCTP after labeling, in a chase step, only slightly increased the length of the fragments. No further modifications of the protocol, for example different amounts of random primers or the use of different enzymes, improved the quality of the results (not shown). These observations correlate well with what is generally known about the random priming reaction $(1,8,9)$.

Although our experience with $B$. subtilis gDNA clearly indicated improved hybridization properties of the labeled probe with the array, we cannot exclude that this effect is somehow related to the composition (i.e., GC/AT content) of the genome under investigation. In our case, alkali denaturation appeared to be a simple alternative to the usual methods of genome fragmentation, including sonication. The results were highly reproducible over more than 40 hybridization experiments with B. subtilis gDNA. The method we suggest avoids any DNA fragmentation suggested by commonly used protocols for gDNA labeling. Moreover, it only involves a slight increase in handling of the material compared to classical random priming (1), and no additional expensive reagents are needed. Our method may also be useful for other applications that require random primer labeling of complex samples, for example, to detect differences between bacterial strains (10) as a method for quality control (11) or normalization of a DNA array (12), to generate random primer genomic libraries (13), and so on.

\section{REFERENCES}

1.Feinberg, A.P. and B. Vogelstein. 1983. A technique for radiolabeling DNA restriction endonuclease fragments to high specific activity. Anal. Biochem. 132:6-13.

2.Eickhoff, H., J. Schuchhardt, I. Ivanov, S. Meier-Ewert, J. O'Brien, A. Malik, N. Tandon, E.W. Wolski, et al. 2000. Tissue gene expression analysis using arrayed normalized cDNA libraries. Genome Res. 10:1230-1240.

3.Eickhoff, H., I. Ivanov, M. Kietzmann, E. Maier, M. Kalkum, D. Bancroft, and $\mathbf{H}$. Lehrach. 1999. Robotic equipment and microsystem technology in biological research, p. 17-30. In J.M. Köhler, T. Mejevaia, and H.P. Saluz (Eds.), Microsystem Technology: A Powerful Tool for Biomolecular Studies. Birkhäuser Verlag, Berlin.
4.Stulke, J., R. Hanschke, and M. Hecker. 1993. Temporal activation of $\beta$-glucanase synthesis in Bacillus subtilis is mediated by the GTP pool. J. Gen. Microbiol. 139:20412045.

5.Sambrook, J. and D.W. Russell. 2001. Molecular Cloning: A Laboratory Manual. CSH Laboratory Press, Cold Spring Harbor, NY.

6.Lindahl, T. 1993. Instability and decay of the primary structure of DNA. Nature 362:709715 .

7.Gustafson, C.E., R.A. Alm, and T.J. Trust. 1993. Effect of heat denaturation of target DNA on the PCR amplification. Gene 123:241-244.

8.Feinberg, A.P. and B. Vogelstein. 1984. A technique for radiolabeling DNA restriction endonuclease fragments to high specific activity. Addendum. Anal. Biochem. 137:266267.

9.Mackey, J., M. Darfler, P. Nisson, and A. Rashtchian. 1993. Use of random primer extension for concurrent amplification and nonradioactive labeling of nucleic acids. Anal. Biochem. 212:428-435.

10.Salama, N., K. Guillemin, T.K. McDaniel, G. Sherlock, L. Tompkins, and S. Falkow. 2000. A whole-genome microarray reveals genetic diversity among Helicobacter pylori strains. Proc. Nat. Acad. Sci. USA 97:1466814673.

11.Richmond, C.S., J.D. Glasner, R. Mau, H. Jin, and F.R. Blattner. 1999. Genome-wide expression profiling in Escherichia coli $\mathrm{K}-12$. Nucleic Acids Res. 27:3821-3835.

12.Talaat, A.M., S.T. Howard, W.T. Hale, R. Lyons, H. Garner, and S.A. Johnston. 2002. Genomic DNA standards for gene expression profiling in Mycobacterium tuberculosis. $\mathrm{Nu}-$ cleic Acids Res. 30:e104.

13.Rohwer, F., V. Seguritan, D.H. Choi, A.M. Segall, and F. Azam. 2001. Production of shotgun libraries using random amplification. BioTechniques 31:108-118.

We would like to thank Matthias Borgmann and Oliver Herde for array production and Ruth Eytner for the technical assistance. We would like to thank Bernd Hutter for preparation of B. subtilis cultures and providing different DNA samples. We appreciate very much the suggestions made by Avril Arthur-Goettig and anonymous referees. Address correspondence to Dr. Igor Ivanov, GPC Biotech AG, Fraunhoferstr. 20, 82152, Martinsried/ Munich, Germany. e-mail: igorivanov@ gpc-biotech.com

Received 25 November 2002; accepted 27 January 2003.

Peter Amon and Igor Ivanov

GPC Biotech AG

Martinsried/Munich, Germany 